Bentham open
CrossMark

REVIEW ARTICLE

\title{
Visual Acuity Improvement in Continuous vs Divided Occlusion in Anisometropic Amblyopia
}

\author{
Irawati Irfani ${ }^{*}$, Feri Feriyanto, Primawita Oktarima and Arief Kartasasmita \\ Department of Ophthalmology, Universitas Padjadjaran/Cicendo Eye Hospital, Bandung, West Java, Indonesia
}

Received: September 20, 2017

Revised: December 29, 2017

Accepted: January 22, 2018

\section{Abstract:}

\section{Purpose:}

To compare visual acuity improvement between continuous and split part-time occlusion for the treatment of moderate and severe anisometropic amblyopia.

\section{Methods:}

Randomised clinical trials in 6 - 13 y.o children with moderate and severe anisometropic amblyopia. Each patient was consecutively selected with continuous or split part-time occlusion. Best corrected visual acuity's improvement was followed up to six weeks and statistical data were analyzed using chi square and unpaired t-test.

Results:

Best corrected visual acuity's improvement was comparable between continuous and split part-time occlusion $(0.20 \pm 0.27 v \mathrm{~s}$ $0.21 \pm 0.25 ; \mathrm{p}=0.79$ ).

\section{Conclusion:}

Split part-time occlusion may be considered as an alternative treatment for moderate and severe anisometropic amblyopia treatment.

Keywords: Part-time occlusion, Full time occlusion, Amblyopia anisometropia, Visual acuity, Divided occlusion, Continuous occlusion.

\section{INTRODUCTION}

Occlusion therapy is still the treatment of choice for anisometropic refractive amblyopia [1,2]. Amblyopia may cause permanent universal vision loss in children. The prevalence of amblyopia in school-aged children in the world is $2 \%[1,3-5]$. Compliance is an important aspect in undergoing occlusion therapy. Several studies were conducted to increase treatment compliance for occlusion therapy, by dividing the occlusion half time continuously or divided [6 - 8]. This study aimed to compare the increase of visual acuity on moderate and severe anisometropic amblyopia between continuous occlusion half time and divided occlusion half time in order to assess its effectiveness as an alternative therapy.

\section{METHODS}

The study was a controlled randomized clinical trial on patients with anisometropic refractive amblyopia aged 6 13 years from pediatric ophthalmology clinic in tertiary eye hospital, Bandung, Indonesia. The inclusion criteria were moderate and severe anisometropic amblyopia (with visual acuity in eye with amblyopia $>0.3 \log$ Mar, visual acuity

\footnotetext{
* Address correspondence to this author at the Department of Ophthalmology, Universitas Padjadjaran/Cicendo Eye Hospital, Bandung, West Java, Indonesia; Tel: +62224210883; Fax: +62224210883; E-mails: irawati.irfani@unpad.ac.id, a.kartasasmita@unpad.ac.id
} 
difference between both eyes $\geq 0.2$ unit logMar), had worn adjusted correction glasses for at least 4 weeks, had not received prior therapy for amblyopia. The exclusion criterion was patient being uncooperative during ophthalmological examination. The study was conducted upon approval from Ethics Committee of Medical Faculty Padjadjaran University.

The patients were divided into 2 groups using random blocks permutation, on the first group continuous half time occlusion was performed and on the second divided half time occlusion was performed. Occlusion was performed using patch treatment as shown in Fig. (1). Continuous occlusion was performed continuously for 4 hours a day and divided occlusion was performed for 2 hours twice a day with an interval of 2 hours. The observation was performed for 6 weeks, assessing the visual acuity after usage of correction glasses for 4 weeks, visual acuity was performed on $2^{\text {nd }}, 4^{\text {th }}$, and $6^{\text {th }}$ week, while undergoing occlusion therapy. The visual acuity was evaluated using logMar chart from 4 meters distances. Compliance of treatment was observed by filling in the activity calendar accompanied with patients' parents while undergoing occlusion therapy. Treatment compliance was divided into 3 categories: good ( $>85 \%$ occlusion time), moderate ( $70-85 \%$ occlusion time), and bad ( $<70 \%$ occlusion time). 0.05 .

Statistical analyses used in this study were Chi Square test and unpaired t-test. The significance of the study $p<$

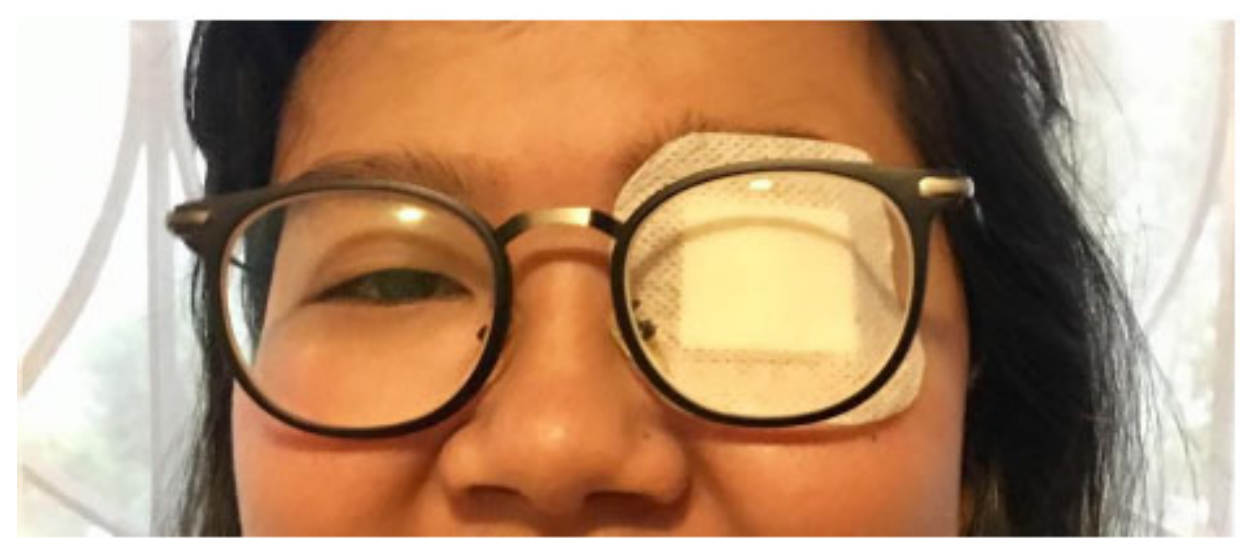

Fig. (1). Patch treatment.

\section{RESULTS}

There were 30 subjects in the continuous occlusion group and 31 subjects in the divided occlusion group. Characteristics of the subjects are shown in Table $\mathbf{1 .}$

Table 1. Characteristics of study subjects.

\begin{tabular}{|c|c|c|c|}
\hline Characteristics & $\begin{array}{l}\text { Continuous half time } \\
\qquad \mathbf{n}=\mathbf{3 0}\end{array}$ & $\begin{array}{l}\text { Divided half time } \\
\quad \mathrm{n}=31\end{array}$ & P-value \\
\hline $\begin{array}{l}\text { Gender } \\
\cdot \text { Men } \\
\text { • Women }\end{array}$ & $\begin{array}{l}15(50 \%) \\
15(50 \%)\end{array}$ & $\begin{array}{l}15(48 \%) \\
16(52 \%)\end{array}$ & 0.90 \\
\hline $\begin{array}{c}\text { Age (years) } \\
\cdot \text { Mean } \pm \text { SD }\end{array}$ & $9.9 \pm 2.5$ & $9.6 \pm 2.4$ & 0.64 \\
\hline $\begin{array}{c}\text { Mother's education } \\
\text { • Primary school } \\
\text { • Middle school } \\
\text { • Secondary school } \\
\text { - Graduate / postgraduate }\end{array}$ & $\begin{array}{c}5(17 \%) \\
7(23 \%) \\
13(43 \%) \\
5(17 \%)\end{array}$ & $\begin{array}{c}6(19 \%) \\
5(16 \%) \\
15(49 \%) \\
5(16 \%)\end{array}$ & 0.91 \\
\hline Refraction adaptation (weeks) & $4.9 \pm 0,5$ & $4.6 \pm 0.5$ & 0.66 \\
\hline $\begin{array}{c}\text { Amblyopia severity } \\
\cdot \text { Moderate } \\
\cdot \text { Severe }\end{array}$ & $\begin{array}{l}17(61 \%) \\
13(39 \%)\end{array}$ & $\begin{array}{l}11(39 \%) \\
20(61 \%)\end{array}$ & 0.10 \\
\hline
\end{tabular}


(Table 1) contd.....

\begin{tabular}{|c|c|c|c|}
\hline Characteristics & $\begin{array}{l}\text { Continuous half time } \\
n=30\end{array}$ & $\begin{array}{l}\text { Divided half time } \\
\mathrm{n}=31\end{array}$ & P-value \\
\hline $\begin{array}{c}\text { Initial visual acuity }(\operatorname{logMar}) \\
\cdot \text { Dominant eye }(\text { Mean } \pm \text { SD) } \\
\text { • Amblyopic eye }(\text { Mean } \pm \text { SD) } \\
\text { - Interocular visual acuity difference }(\text { Mean } \pm \text { SD) }\end{array}$ & $\begin{array}{l}0.24 \pm 0.11 \\
0.63 \pm 0.25 \\
0.40 \pm 0.27\end{array}$ & $\begin{array}{c}0.22 \pm 0.14 \\
0.71 \pm 0.26 \\
0.48 \pm 0.27\end{array}$ & $\begin{array}{l}0.68 \\
0.26 \\
0.20\end{array}$ \\
\hline Compliance & $92 \% \pm 18 \%$ & $88 \% \pm 16 \%$ & 0.45 \\
\hline
\end{tabular}

Occlusion was performed on the subjects for 6 weeks with 2 different occlusion techniques: continuous half time occlusion and divided half time occlusion. The resulting visual acuity and mean of visual acuity increase is shown in Table 2.

Table 2. Initial visual acuity and increase of visual acuity of amblyopic eye in both groups after 6 weeks of treatment.

\begin{tabular}{|c|c|c|c|}
\hline Visual acuity variable (logMar) & $\begin{array}{c}\text { Continuous half time } \\
\mathbf{n = 3 0}\end{array}$ & $\begin{array}{c}\text { Divided half time } \\
\mathbf{n}=\mathbf{3 1}\end{array}$ & P-value \\
\hline Visual acuity (Mean \pm SD) & $0.35 \pm 0.26$ & $0.38 \pm 0.22$ & 0.72 \\
\hline $\begin{array}{c}\text { Increase of visual acuity } \\
\text { (Mean } \pm \text { SD) }\end{array}$ & $0.20 \pm 0.27$ & $0.21 \pm 0.25$ & 0.79 \\
\hline
\end{tabular}

No significant differences were found in increase of visual acuity and visual acuity difference between continuous half time occlusion group and divided half time occlusion group. $(0.35 \pm 0.26 v s 0.38 \pm 0.22(\mathrm{p}=0.72) ; 0.20 \pm 0.27 v s$ $0.21 \pm 0.25(\mathrm{p}=0.79)$. The end result of visual acuity and mean of increase of visual acuity on moderate and severe amblyopia groups are shown in Table $\mathbf{3}$.

Table 3. Visual acuity and increase of visual acuity in amblyopic eye after 6 weeks Of treatment according to amblyopia severity.

\begin{tabular}{|c|c|c|c|}
\hline \multirow{2}{*}{$\begin{array}{c}\text { Variables } \\
\text { Amblyopia severity }\end{array}$} & \multicolumn{2}{|c|}{ Groups } & \multirow[t]{2}{*}{ P-values } \\
\hline & $\begin{array}{c}\mathbf{A} \\
(\mathrm{n}=\mathbf{3 0})\end{array}$ & $\begin{array}{c}\text { B } \\
(n=31)\end{array}$ & \\
\hline Moderate (0.3-0.6 logMar) $(\mathrm{n}=28)$ & $0.22 \pm 0.1$ & $0.20 \pm 0.1$ & 0.64 \\
\hline Increase of visual acuity (Mean \pm SD) & $0.25 \pm 0.05$ & $0.27 \pm 0.08$ & 0.42 \\
\hline Severe $(>0.6 \operatorname{logMar})(\mathrm{n}=33)$ & $0.53 \pm 0.31$ & $0.47 \pm 0.21$ & 0.52 \\
\hline Increase of visual acuity $($ Mean \pm SD) & $0.30 \pm 0.14$ & $0.37 \pm 0.15$ & 0.19 \\
\hline
\end{tabular}

Notes: A: Continuous half time occlusion B: Divided half time occlusion

Average of visual acuity in moderate amblyopia group after 6 weeks of occlusion treatment in group A was $0.22 \pm 0.1 \log$ Mar and in group B was $0.20 \pm 0.1 \log$ Mar. In severe amblyopia, the mean visual acuity after 6 weeks of occlusion treatment in group A was $0.53 \pm 0.31 \log$ Mar and in group B was $0.47 \pm 0.21 \log$ Mar. There was no significant difference between the visual acuity of moderate and severe amblyopia in both groups $(p=0.64 ; \mathrm{p}=0.52)$. The average increase of visual acuity in moderate amblyopia after 6 weeks of occlusion therapy in group A was $0.25 \pm 0.05$ logmar and in group B was $0.27 \pm 0.08$ logMar. The average increase of visual acuity in severe amblyopia in group A was $0.30 \pm 0.14 \log$ Mar and in group B was $0.37 \pm 0.15 \log$ Mar. There was no significant difference in increase of visual acuity between moderate and severe amblyopia in both groups. $(p=0.42 ; p=0.19)$.

Table 4. LogMar conversion.

\begin{tabular}{|c|c|c|c|}
\hline Foot & Metre & Decimal & LogMAR \\
\hline $\mathbf{2 0} / \mathbf{2 0 0}$ & $6 / 60$ & 0.10 & 1.00 \\
\hline $\mathbf{2 0} / \mathbf{1 6 0}$ & $6 / 48$ & 0.125 & 0.90 \\
\hline $\mathbf{2 0} / \mathbf{1 2 5}$ & $6 / 38$ & 0.16 & 0.80 \\
\hline $\mathbf{2 0 0 / 1 0 0}$ & $6 / 30$ & 0.20 & 0.70 \\
\hline $\mathbf{2 0} / \mathbf{8 0}$ & $6 / 24$ & 0.25 & 0.60 \\
\hline $\mathbf{2 0} / \mathbf{6 3}$ & $6 / 19$ & 0.32 & 0.50 \\
\hline $\mathbf{2 0} / \mathbf{5 0}$ & $6 / 15$ & 0.40 & 0.40 \\
\hline $\mathbf{2 0} / \mathbf{4 0}$ & $6 / 12$ & 0.50 & \\
\hline
\end{tabular}


(Table 4) contd.....

\begin{tabular}{|c|c|c|c|}
\hline Foot & Metre & Decimal & LogMAR \\
\hline $\mathbf{2 0} / \mathbf{3 2}$ & $6 / 9.5$ & 0.63 & 0.20 \\
\hline $\mathbf{2 0} / \mathbf{2 5}$ & $6 / 7.5$ & 0.80 & 0.10 \\
\hline $\mathbf{2 0} / \mathbf{2 0}$ & $6 / 6$ & 1.00 & 0.00 \\
\hline $\mathbf{2 0} / \mathbf{1 6}$ & $6 / 4.8$ & 1.25 & -0.10 \\
\hline $\mathbf{2 0} / \mathbf{1 2 . 5}$ & $6 / 3.8$ & 1.60 & -0.20 \\
\hline $\mathbf{2 0} / \mathbf{1 0}$ & $6 / 3$ & 2.00 & -0.30 \\
\hline
\end{tabular}

\section{DISCUSSION}

Kane et al., had compared treatment compliance of continuous occlusion and divided occlusion therapy and had shown the identical increase of visual acuity in both groups $(p=0.82)$. [9] This study has shown that increase of visual acuity was not significantly different between both treatments $(0.35 \pm 0.26 \log$ ar $v s 0.38 \pm 0.22 \log$ Mar; $\mathrm{p}=0.72)$. This is different with the study conducted by Bhoompally et al, whose result was the visual acuity in the group that had received continuous occlusion therapy was better than the group that had received divided occlusion therapy $(0.51 \pm 0.26$ $\log$ Mar $v s 0.59 \pm 0.04 \log$ Mar; $\mathrm{p}=0.27)$. [6] Different results were also acquired compared to the same study, in the group that had received continuous occlusion therapy had a higher increase of visual acuity compared to the group that had received divided occlusion therapy. $(0.47 \pm 0.04 \log$ Mar $v s 0.37 \pm 0.05 \log$ Mar; $\mathrm{p}=0.15)$ [6] This study had shown that the mean of visual acuity increase on the continuous occlusion group was not significantly different compared to the divided occlusion group. $(0.21 \pm 0.25 \log$ Mar $v s 0.20 \pm 0.27 \log$ Mar; $\mathrm{p}=0.79)$.

This study had shown that, in moderate amblyopia, the mean of end visual acuity and the increase of visual acuity was higher in the divided occlusion group compared to the continuous occlusion group after 6 weeks of treatment. Meanwhile, in severe amblyopia, there was a difference, although statistically insignificant, in mean of end visual acuity and the increase of visual acuity between both groups.

The end visual acuity and mean increase of visual acuity in severe amblyopia was higher in divided occlusion group compared to continuous occlusion group. This may be caused due to higher interocular visual acuity difference in the divided occlusion group compared to the continuous occlusion group (the visual acuity in amblyopic eye is worse compared to continuous occlusion group), making the occlusion therapy effects on visual acuity becoming more noticeable in this group.

Several alternatives to improve comfort during occlusion therapy is to minimalize occlusion time by dividing the occlusion time and finding an alternative method for occlusion. One of them is by dividing occlusion time into several parts to increase treatment compliance. One of the most critical aspect in amblyopia treatment successistreatmentcompliance.

According to a study conducted by Al-Zuhaibi et al. suggested that with bad treatment compliance affect success chance in treating amblyopia, with increase of visual acuity was strongly associated with treatment compliance in occlusion therapy $(\mathrm{p}=0.08)[10]$

A study conducted by ATS 2B had found that the end visual acuity and increase of visual acuity in patients with moderate amblyopia in occlusion half time for 2 hours was as good as 6 hours of occlusion half time [7]. Identical results were acquired in severe amblyopia, according to a study conducted by ATS $2 \mathrm{~A}$, that had found the end visual acuity and increase of visual acuity in patients with severe amblyopia were better in half time occlusion for 6 hours compared to full occlusion. ${ }^{7}$ This study had indicated that shorter duration of occlusion increases therapy compliance. Singh et al, found that half time occlusion on mild amblyopia for 2, 4, and 6 hours were identically effective with full occlusion, while in severe amblyopia it has been shown that full occlusion and 6 hours occlusion were more effective compared to 2 hours occlusion [11].

Evaluated from compliance aspect, Jessica Kane et al. found the compliance in continuous occlusion group to be better compared to divided occlusion group $(\mathrm{p}=0.023)$ [9]. According to a study conducted by Bhoompally et al. however, the compliance in divided occlusion (82\%) was better compared to continuous occlusion (75\%) [6]. The result differed with this study, where the compliance in continuous occlusion group (92\%) was better compared to divided occlusion group $(88 \%)$ although the difference was not statistically significant $(p=0.24)$. The difference of compliance levels may be caused by the duration of observation on both of the studies. The study conducted by Bhoompally observed the patient for 6 months compared to 6 weeks (which was performed in this study). Occlusion therapy for a 
long period of time may cause discomfort due to usage of occluder, thus reducing the treatment compliance. Additionally, usage of half time occlusion therapy may fit better to the patients' schedule. In this study, the compliance was found to be good and moderate with an increase of visual acuity occurred in subjects with moderate and severe amblyopia.

The limitations of the study were the small sample size and relatively short duration of observation. The difference in adaptation period of corrective glasses (between 4-16 weeks) may be a confounding factor in the increase of visual acuity in occlusion therapy.

\section{CONCLUSION}

In this study, the half time occlusion therapy resulted in an increase of visual acuity identical with full time occlusion therapy in anisometropic moderate and severe amblyopia. There were no difference in compliance between the group with continuous half time occlusion and the group with divided half time occlusion. Half time occlusion therapy may be used as an alternative for anisometropic moderate and severe amblyopia therapy.

\section{ETHICS APPROVAL AND CONSENT TO PARTICIPATE}

The study was conducted upon approval from Ethics Committee of Medical Faculty Padjadjaran University.

\section{HUMAN AND ANIMAL RIGHTS}

No Animals were used in this research. All human research procedures followed were in accordance with the ethical standards of the committee responsible for human experimentation (institutional and national), and with the Helsinki Declaration of 1975, as revised in 2008.

\section{CONSENT FOR PUBLICATION}

A written informed consent was obtained from all patients when they were enrolled.

\section{CONFLICT OF INTEREST}

The authors declare no conflict of interest, financial or otherwise.

\section{ACKNOWLEDGEMENTS}

Declared none.

\section{REFERENCES}

[1] Yip WW, Fan DS. Amblyopia: An Overview. Hong Kong Medical Bulletin 2007; 12: 22-4.

[2] Murthy R. Amblyopia-current trends in management. Kerala J of Ophthalmol 2008; 20: 139-43.

[3] Woldeyes A, Girma A. Profile of amblyopia at the pediatric ophthalmology clinic of menilik II hospital, addis ababa. Ethiop J Health Dev 2008; 22(2): 201-5.

[4] Donahue SP. The relationship between anisometropia, patient age, and the development of amblyopia. Trans Am Ophthalmol Soc 2005; 103: 313-36. [PMID: 17057809]

[5] Yekta A, Fotouhi A, Hashemi H, et al. The prevalence of anisometropia, amblyopia and strabismus in schoolchildren of Shiraz, Iran. Strabismus 2010; 18(3): 104-10. [http://dx.doi.org/10.3109/09273972.2010.502957] [PMID: 20843187]

[6] Bhoompally VR, Gupta A, Mittal V, Sachdeva V, Kekunnaya R. Split hours part time patching versus continuous wear part time patching in moderate to severe anisometropic amblyopia. AAPOS J 2012; p. 16.

[7] Holmes JM, Kraker RT, Beck RW, et al. A randomized trial comparing of prescribed patching regimens for treatment of severe amblyopia in children. Ophthalmology 2003; 110: 2057-87.

[8] Repka MX, Beck RW, Holmes JM, et al. A randomized trial comparing of prescribed patching regimens for treatment of moderate amblyopia in children. Ophthalmology 2003; 136(4): 620-9.

[9] Kane J, Biernacki R, Fraine L, Fukuda N, Haskins K, Morrison DG. Patching compliance with full-time vs. part-time occlusion therapy. Am Orthopt J 2013; 63: 19-23.

[http://dx.doi.org/10.3368/aoj.63.1.19] [PMID: 24260803]

[10] Al-Zuhaibi S, Al-Harthi I, Cooymans P, Al-Busaidi A, Al-Farsi Y, Ganesh A. Compliance of amblyopic patients with occlusion therapy: A pilot study. Oman J Ophthalmol 2009; 2(2): 67-72. 
[http://dx.doi.org/10.4103/0974-620X.53035] [PMID: 20671832]

[11] Singh I, Sachdev N, Brar GS, Kaushik S. Part-time occlusion therapy for amblyopia in older children. Indian J Ophthalmol 2008; 56(6): 459-63.

[http://dx.doi.org/10.4103/0301-4738.43365] [PMID: 18974515]

(C) 2018 Irfani et al.

This is an open access article distributed under the terms of the Creative Commons Attribution 4.0 International Public License (CC-BY 4.0), a copy of which is available at: https://creativecommons.org/licenses/by/4.0/legalcode. This license permits unrestricted use, distribution, and reproduction in any medium, provided the original author and source are credited. 